\title{
Sobre el léxico de origen mesopotámico (sumerio y acadio) en las lenguas eslavas, en español y en otras varias lenguas
}

\author{
Salustio Alvarado \\ Universidad Complutense de Madrid \\ salvarad@filol.ucm.es
}

Recibido: Diciembre de 2011

Aceptado: Junio de 2012

\section{Resumen}

Las lenguas mesopotámicas, sumerio y acadio, se cuentan entre las más antiguas lenguas de cultura de la humanidad. Aunque, obviamente, en las lenguas eslavas no puede existir ningún préstamo directo del sumerio o del acadio, dado que estas lenguas se extinguieron hace muchísimos siglos, es relativamente abundante el léxico de este origen llegado a través del hebreo, el arameo, el árabe, el griego, el latín, etc.

Palabras clave: lengua sumeria, lengua acadia, lenguas eslavas, préstamos léxicos

About the vocabulary of Mesopotamian (Sumerian and Akkadian) origin in the Slavonic languages, Spanish and other languages

\begin{abstract}
Mesopotamic languages, Sumerian and Akkadian, are among the oldest culture languages of mankind. Although in Slavonic languages there cannot be, for obvious reasons, any direct loanwords from them, as they disappeared many centuries ago, words of Sumerian and Akkadian origin are relatively abundant, having come through Hebrew, Aramean, Arabic, Greek, Latin, etc.
\end{abstract}

Key words: Sumerian language, Akkadian language, Slavonic languages, loanwords

Junto con la lengua egipcia, de la que nos ocupamos en su momento (vid. ALVARADO 2006 y 2007), las lenguas mesopotámicas, sumerio y acadio, se cuentan igualmente entre las más antiguas lenguas de cultura de la humanidad. Aunque, obviamente, en los idiomas hablados hoy día no puede existir ningún préstamo directo del sumerio o del acadio, dado que estas lenguas se extinguieron hace muchísimos siglos, es, sin embargo, relativamente abundante el léxico de esta procedencia llegado a través del hebreo, el arameo, el árabe, el griego, el latín, etc. Éste, por tanto, será el tema del presente artículo en el que, sin pretender ser exhaustivo, se estudiarán los vocablos de dicho origen en las lenguas eslavas, bastantes de ellos, por tratarse de cultismos universales, encuentran correspondencia en español, así como en otras muchas lenguas. 
Hacia el año 3200 AC la parte meridional de lo que hoy día es Iraq y que en la antigüedad se conocía como Mesopotamia, es decir, la tierra entre los ríos Tigris y Éufrates, estaba habitada por los llamados sumerios, pueblo de origen desconocido que hablaba una lengua inclasificable, que, entre otros rasgos, se caracterizaba por ser aglutinante y ergativa y a la que infructuosamente se han querido buscar relaciones de parentesco con las lenguas dravídicas, sino-tibetanas, caucásicas, etc. Particularmente pintoresca es la hipótesis de que el sumerio habría sido el antepasado de las lenguas fino-ugrias.

A esta población sumeria se fueron juntando oleadas de semitas, que adoptaron la cultura de los sumerios, empezando por la escritura, si bien, al hacerse mayoritarios acabaron por imponer su lengua, el acadio, de tal modo que hacia el año 1900 AC se supone que el sumerio dejó de ser lengua viva. No obstante, debido a su enorme prestigio cultural, el sumerio se siguió estudiando en las escuelas de escribas (de lo que dan testimonio las numerosas "cartillas" de aprendizaje conservadas en tablillas de arcilla) y empleando como lengua litúrgica y de cultura (más o menos como el latín en la Europa medieval y renacentista o como el sánscrito en la India) hasta prácticamente el fin de la civilización mesopotámica, cuya literatura se conserva mayoritariamente en doble versión, sumeria, por un lado, y acadia, por otro.

Por su parte, la lengua acadia, en sus dos variantes dialectales, asiria y babilónica, conocería su época de esplendor, no sin altibajos, desde aproximadamente el 2350 al $539 \mathrm{AC}$, fecha de la conquista de Babilonia por los persas, que marca la sustitución del acadio por el arameo como lengua diplomática y comercial del Medio Oriente.

La dilatada convivencia del sumerio con la lengua acadia hizo que ésta evolucionara de una manera notablemente diferente a la del resto de las lenguas semíticas, siendo uno de las características más señaladas de esta evolución la reducción de las seis laringales $\mathbf{P}, \boldsymbol{h}, \boldsymbol{h}, \boldsymbol{b}, \mathfrak{S}$ y $\dot{\mathbf{g}}$, las cuales, según el testimonio del árabe, se reconstruyen para el semítico común, a sólo dos, $\mathbf{P}$ y $\boldsymbol{b}$, por lo menos en lo que se refiere a la grafía, pues, en lo referente a la presencia de las laringales en los préstamos a otras lenguas semíticas, los datos son bastante contradictorios, siendo un factor esencial la diacronía.

La escritura de los sumerios en un principio fue pictográfica, pero al generalizarse el empleo de tablillas de arcilla fresca, que luego se secaban a sol o se cocían, como soporte de los escritos, los pictogramas se fueron estilizando y esquematizando, reduciéndose a una combinación de marcas con diversa orientación que el punzón del escriba dejaba sobre la arcilla. Al tener dichas marcas forma de cuña, este tipo de escritura se ha denominado cuneiforme.

La escritura cuneiforme, a despecho de su complejidad, resultaba bastante apropiada para escribir la lengua sumeria, dado que, como ya se ha dicho, era aglutinante y la mayoría de las palabras básicas eran monosilábicas, como, p. ej., $l u_{2}$

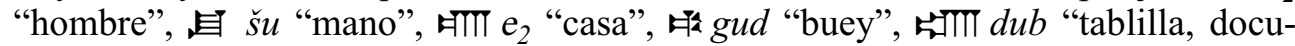
mento", 旦 gal "grande", esta base, se creaban nuevos vocablos por composición, p. ej. जाTा- $e_{2}$-gal "palacio, templo", ज्ञा medio del prefijo ज्ञा nam- se formaban sustantivos abstractos, p. ej. ज्ञात nam-lugal "realeza", natा nam-dam "condición de casada", etc. Ciertos sustan- 
tivos se empleaban, escritos delante o detrás de cada palabra, como determinativos para clasificarla de un modo genérico en cuanto a su significado, p. ej. ${ }^{\circ}$ dig̃ir "dei-

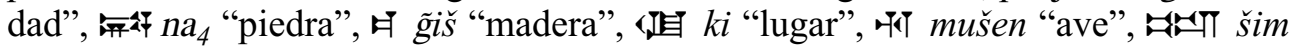
"planta", etc. En la transliteración los determinativos se colocan como superíndices,

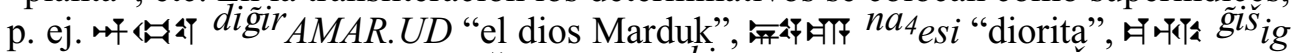

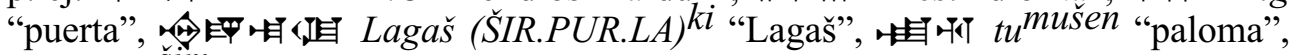

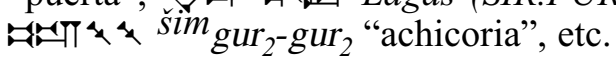

Antes de seguir adelante, hay que advertir que no se sabe a ciencia cierta cómo se pronunciaba el sumerio. La transliteración que se emplea habitualmente es un convencionalismo pergeñado por los sumerólogos de finales del siglo XIX y principios del XX. Según esta transliteración, los fonemas del sumerio habrían sido $a, b, d, e$, $g, \tilde{g}, h, i, k, l, m, n, p, r, s, \breve{s}, t, u, z$. Sin embargo, es más que probable que en sumerio no se diera entre las oclusivas una oposición sorda/sonora, sino más bien una oposición sorda fuerte/sorda lene o, en su caso, sorda aspirada/sorda no aspirada, lo que se infiere del consonantismo de ciertos préstamos sumerios en las lenguas semí-

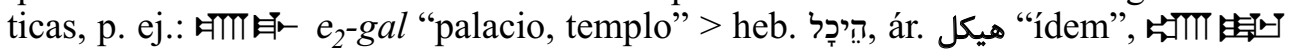

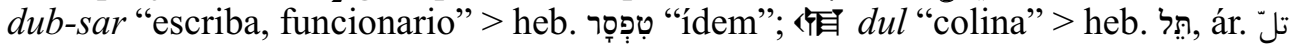

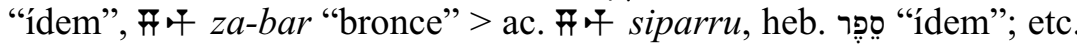

Otro rasgo llamativo de la escritura sumeria es la abundancia de grafías homófonas, que en la transliteración se marcan por medio de subíndices numéricos, p. ej. Gł

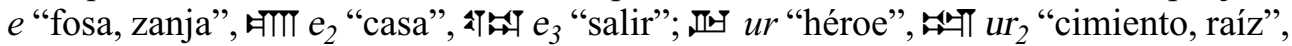
$u r_{3}$ "salir", JIr $u r_{4}$ "temblar", $u r_{5}$ "hígado", etc. Esta circunstancia ha hecho suponer que el sumerio habría sido una lengua tonal.

$\mathrm{Al}$ igual de lo ocurrido a los japoneses con la escritura china, asirios y babilonios adoptaron, dado, como ya se ha dicho, el enorme prestigio cultural de la civilización sumeria, y adaptaron la escritura cuneiforme para escribir el acadio, a pesar de que ésta era totalmente inapropiada para representar una lengua semítica, y lo hicieron tanto tomando las palabras sumerias a modo de ideogramas, como empleando el silabario sumerio según su valor fonético, ajustándolo mal que bien a la pronunciación del acadio. Así, p. ej., lu lee en acadio šarru (cf. heb. wש "príncipe") o bien la palabra acadia se puede escribir combinando las sílabas sar y $r$ sill $r u$, aunque también cabía la posibilidad de representar esta palabra en acadio por medio del ideograma ". Del mismo modo, 繋 gud "buey" se lee en acadio Palpu (cf. ug. $\infty$ אוा "ídem") o bien la palabra acadia se puede escribir combinando las sílabas al y y te el híbrido

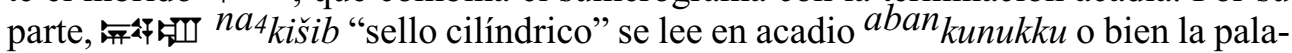

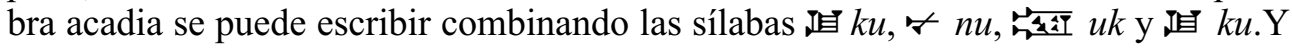
como estos ejemplos, otros muchos.

Tras esta breve y somera introducción pasemos al tema central de nuestro trabajo.

Mucho antes de que el caballo, el camello y, no digamos, el elefante fueran domesticados, la primera bestia de carga al servicio del hombre fue el humilde y sufrido borrico (Equus asinus). La civilización sumeria se desarrollo a lomo de jumento, que ayudó a labrar la tierra, a abrir rutas comerciales e incluso fue uncido a los carros de guerra, de lo que da testimonio gráfico el "estandarte de Ur" $( \pm 2500$ 
a. C.) conservado en el Museo Británico. No es, por tanto, extraño que la palabra de origen sumerio quizá más extendida sea precisamente la hace referencia a este perisodáctilo solípedo. "Asno" en sumerio es anše, vocablo que se fue extendiendo por Oriente Medio y por la cuenca mediterránea y pasó como "palabra viajera" tanto al gr. ővo $<$ *oøovo, como al arm. $\boldsymbol{t}_{2}$ y al lat. asinus. Que asinus es un préstamo queda demostrado por el hecho de que la s intervocálica no ha rotado. Del latín pasó a al gótico como jsinns y del gótico a las lenguas eslavas: a.esl. ocbrh, esl. ecl. о̀с́́ız, rus. осёл, brus. асёл, ucr. осел, pol. osiol, ch. osel, eslc. osol, eslv. osel, srcr. osao, búlg. осел.

Como se ha visto más arriba, 胎 $g u d$, que también puede transliterarse como $g u_{4}$, significa "buey", palabra que, dejando aparte el problema de la existencia o no de oclusivas sonoras en sumerio, presenta un asombroso parecido, tal como, entre otros, señala el Diccionario Etimológico Episquénico (Online Etymology Dictionary) de Douglas HARPER, con la raíz indoeuropea $* \boldsymbol{g}^{\boldsymbol{w}} \boldsymbol{w} \boldsymbol{w}$-, que se recons-

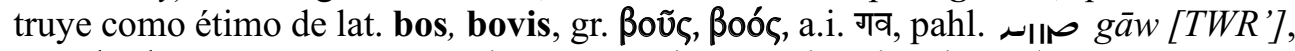
arm. unu, a.a.a chuo y, naturalmente, a.esl. говадо*, esl. есl. говА́до, rus. говядо, ch. hovado, eslc. hovädo, eslv. govedo, sr-cr. govedo, búlg. говедо. Dado que coin-

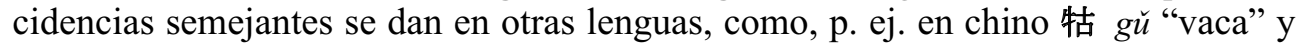
teniendo en cuenta, por un lado, la importancia de la domesticación de los rumiantes cavicornios en general, y de los bóvidos en particular, para el desarrollo de la civilización humana, y que, por otro lado, en lingüística, al igual que en política, no existen las casualidades, hay que pensar que tanto H $^{2} g \boldsymbol{u}_{4}$, como ${ }^{*} \boldsymbol{g}^{\boldsymbol{w}} \boldsymbol{o w}$ - y como 牯 gŭ, son "palabras viajeras" que, dado además su carácter más o menos onomatopéyico, proceden del sustrato más primitivo del lenguaje humano.

Pasando de los animales a las plantas, tenemos, a través del al. Zichorie, y éste de b.lat. cichorea "achicoria", pol. cykorja, en ch. cikorie y en eslc. cigória, con el mismo significado. La palabra latina cichorea procede, a su vez, del gr. kíxopa o kıxópıov "achicoria", vocablo sobre el que CHANTRAINE (1990: 536) afirma taxativamente: "pas d'étymologie". Discrepando radicalmente de tan solemne dislate, en primer lugar afirmamos que el lenguaje empezó cuando ese primate depredador, conocido como Homo sapiens, comenzó a actuar como tal, o puede que mucho antes, con especies antecesoras y colaterales, por lo que toda palabra necesariamente ha de tener su etimología. Que ésta sea, o no, conocida, ése ya es otro problema. En este caso concreto, kixóplov puede proceder, obviamente por vía indirecta, del ac. gur $_{2}$-gur 2 "ídem".

Prosiguiendo con los fitónimos, encontramos: a.esl. ǩrмннъ, esl. ecl. ки́мїнъ, rus. тмин, brus. кмін, uсr. тмин, pol. kmin, ch. kmín, eslc. kmín, eslv. kumina, sr-cr. kim, búlg. кимион, que proceden, en su caso a través del lat. cumīnum y del a.a.a kumîn, del gr. kúplvov y éste, con algún intermediario semítico (cf. ár. كمون, heb.

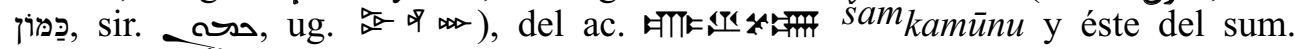

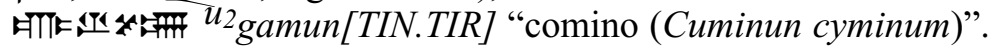

No menor relevancia culinaria tiene la cúrcuma: rus. куркума, brus. куркума, ucr. куркума, pol. kurkuma, ch. kurkuma, eslc. kurkuma, eslv. kurkuma, sr-cr. kurkuma, búlg. куркума, que entró en las lenguas eslavas a través del al. kurku- 
ma, éste lo tomó del latín medieval curcuma, que, a su vez, lo tomó del ár. vocablo que, al igual que sus correspondientes semíticos: heb. حمiֹ حدى , sir, procede del ac. HाF kur-gi-nasar "cúrcuma (Curcuma longa)". Con el mismo origen, pero llegado por distinta vía, tenemos gr. kрókoৎ "azafrán (Crocus sativus)", que da en ruso el arcaísmo крокусъ/крокось "alazor (Carthamus tinctorius)" (ДАЛЬ, II, 1881:197).

Si hay un fitónimo de etimología auténticamente controvertida, éste es, sin duda, “cáñamo" (Cannabis sativa): rus. конопля, brus. каноплі, ucr. конопля, pol. konop, ch. konopí, eslc. konope, eslv. konoplja, sr-cr. konoplja, búlg. коноп, formas que se remontarían a un protoeslavo *kănăp con lit. kanapès, arm. quututu, far. كنف, it. canapa, etc. Es llamativa la palabra italiana canapa, la cual indudablemente procede de una forma dialectal itálica distinta de la del lat. cannabis, que es préstamo del gr. kớvvaßßৎ, que tiene relación etimológica, por un lado, con el doblete del far. كنب, y, por otro, con las formas germánicas, a.nór., HRPI Y, a.a.a hanaf, al. Hanf, a.ing. hænep, ing. hemp, neerl. hennep, etc., que, conforme a la ley de Grimm, presentan la rotación $\mathbf{k} \rightarrow \mathbf{h}, \mathbf{b} \rightarrow \mathbf{p}$ (las formas alto-alemanas también la posterior rotación $\mathbf{p} \rightarrow \mathbf{f}$ ), lo que indica la antigüedad del préstamo, pues se considera que las formas indoeuropeas son de procedencia

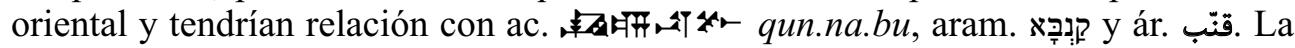

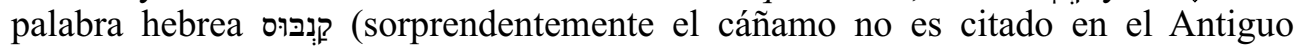
Testamento) con toda probabilidad es préstamo del griego. En sumerio gu "cordón, cuerda, lino, cáñamo" puede presentar un alargamiento gu. está nada claro que exista dependencia etimológica entre el sumerio y las lenguas semíticas e indoeuropeas, cuyo caso, en dicho supuesto, sería un ejemplo típico de "palabra viajera".

Es realmente llamativo que VASMER (1986: III, 312), CHANTRAINE (1990: 493), KLUGE (1995:354), PFEIFER (2000: 505-506) y otros varios den como étimo de конопля/кớvv $\propto \beta$ «ৎ/Hanf, un supuesto sum. ${ }^{* *} k u n i b u$, que no figura ni en el glosario de DELITZSCH (1914), ni en el glosario de ELLERMEIER (1979), ni el diccionario de HALLORAN (2006), por lo que es de suponer que tal palabra sumeria simplemente no existe. El barón VON SODEN (1965: 507) recoge en su diccionario el vocablo kunib(h) $u$, pero se trata de acadio y no de sumerio, y lo define dubitativamente como "eine Wickenart?”, es decir, “una especie de arveja?”. Hay que tener en cuenta que en alemán comúnmente se llama Wicke al guisante de olor (Lathyrus odoratus) y a otras plantas parecidas de la familia de las leguminosas, también llamadas fabáceas, en tanto que el cáñamo pertenece, como su nombre indica, a la familia de las cannabáceas. İtem más, en el Diccionario Asirio del Instituto Oriental de la Universidad de Chicago (Tomo 8, 1971: 539) aparece igualmente el vocablo kunibu, remitiéndonos a kuniphu, cuya definición resulta ser "a pungent garden plant", es decir, "una planta de jardín (de sabor) acre" y, especificando más, en el Diccionario Asirio-Inglés/Ingles-Asirio editado por PARPOLA y WHITING (2007: 51) se define kuniphu como "an alliaceous plant", es decir, "una planta aliácea", habida cuenta de que el género Allium pertenece a la familia de las liliáceas, no de las cannabáceas. Visto lo visto, encontramos en el supuesto sum. ${ }^{* *} k u n i b u$, un caso paradigmático de "etimología fantasma", que va saltando alegremente de dic- 
cionario etimológico en diccionario etimológico y que, para colmo de males, en los últimos tiempos, gracias a las modernas tecnologías, ha proliferado como gremlins en remojo; para comprobarlo, sugerimos al amable lector que en un buscador de internet introduzca kunibu junto con alguna palabra como hemp, Hanf, Cannabis o similar y que cuente los resultados.

Otro semitismo del griego es la palabra Kó́vva "caña", que, a través del fen. $\nless$ $\varphi$ y del ug. $\aleph_{\infty}$, procede del ac. भा qanū y éste de sum. Tा gi(n) "caña". Derivado

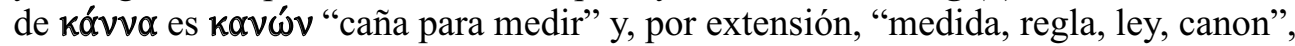
palabra que ha tenido especial fortuna en las lenguas del Oriente Medio. De kavẃv, a través del sir. مس مانون procede el ár. "norma, ley, canon", así como su adjetivo nisbado قانوني "legal, canónico" y también "legista, jurisperito", que da en tur. kanuni, sobrenombre del sultán Süleyman el Magnífico (reg. 1520-1566). Por otro lado,

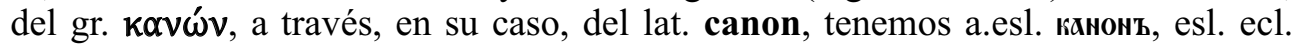
канш́нн, rus. канон, brus. канон, ucr. канон, pol. kanon, ch. kánon, eslc. kánon, eslv. kanon, sr-cr. kanon, búlg. канон, en todas sus acepciones, tanto legales, como litúrgicas y musicales, así como una notable cantidad de derivados, que sería prolijo citar en detalle.

Aumentativo de caña es la palabra cañón que, en su acepción de "paso estrecho o garganta profunda entre dos altas montañas, por donde suelen correr los ríos" ha pasado como hispanismo a algunas lenguas eslavas, v. g. rus. каньон, pol. kanion, ch. y eslc. kaňon, etc. En italiano el término correspondiente a cañón es cannone, que, en su acepción de "pieza de artillería", ha pasado, con intermediación del al. Kanone, a las lenguas eslavas, bien directamente, como, p. ej. ch. y eslc. kanón, o bien por medio de derivados, v. gr. rus. канонада, канонерка, etc.

Cierta relación etimológica con ac. भा qanū tiene la palabra griega kıvvó $\mu \omega \mu$ v, es decir, la canela (Cinnamomum zeylanicum). Como helenismo la palabra кнна. момz puede aparecer en eslavo eclesiástico y antiguo ruso como sinónimo de корн. ца (cf. III Baruc ${ }^{\mathrm{c}}$ IV, 11).

Por lo que se refiere al sésamo, véase ALVARADO (2006: 191).

Pasando del reino vegetal al reino mineral, encontramos: a.esl. сьрекро, esl. ecl. грєвроे, rus. серебро, brus. серебро, ucr. серебро, pol. srebro, ch. stř́ibro, eslc. striebro, eslv. srebro, sr-cr. srebro, búlg. сребро, i.e. "plata" (Ag), que encuentran correspondencia en otras ramas indoeuropeas, p. ej. gót. sاAnвk, al. Silber, ing. silver, lit. sidabras, y quizá también gr. oí́npoৎ "hierro". Según MACHEK (1997: 587) se trataría de un préstamo del ac. 通 ๆ " "platero, orfebre"), aunque es mucho más probable que se trate de un típico caso de palabra viajera de origen desconocido, que penetró en indoeuropeo, en semítico y en otras lenguas (cf. vasc. zillar "plata").

La metalonimia es un campo donde particularmente se dan casos de palabras viajeras y de etimologías controvertidas, como ocurre con el siguiente ejemplo: a.esl. жекъзо, esl. ecl. жєк $3^{\circ}$, rus. железо, brus. жалеза, ucr. желізо, pol. żelazo, ch. železo, eslc. železo, eslv. železo, sr-cr. željezo, búlg. желязо i.e. "hierro" (Fe), que tendría relación etimológica con lit. geležis "hierro" y con gr. $\chi \alpha \Lambda$ kó $\varsigma$ "bronce", vocablos que procederían de un alargamiento $* \boldsymbol{g} \boldsymbol{h} \boldsymbol{e}-(\overline{\boldsymbol{e}})-\boldsymbol{g} \boldsymbol{h}$ de la raíz i.e. ${ }^{*} \boldsymbol{g} \boldsymbol{h} \boldsymbol{e l}$ "ser rojo/amarillo", de la cual igualmente, con grado o y otro alargamiento *g $\boldsymbol{h}_{\boldsymbol{o l}} \boldsymbol{t} \boldsymbol{t}$, tene- 
mos a.esl. злато, esl. ecl. зма́то, rus. золото, brus. золата, ucr. золото, pol. złoto, ch. zlato, eslc. zlato, eslv. zlato, sr-cr. zlato, búlg. злато "oro" (Au), así como letón zèlts y gót. rn $\boldsymbol{\psi} \psi$, al. Gold, etc. y, como préstamo, finés kulta y estonio kuld. En ambos casos significaría "metal rojo o amarillo" y, en el caso del eslavo y el báltico, se habría producido un desplazamiento semántico, perfectamente lógico desde el punto de vista histórico, de "bronce" a "hierro" (cf. a.ing. bræs, ing. brass "bronce, latón" frente a lat. ferrum $<* \boldsymbol{b}^{\boldsymbol{h}}$ ersom). En el caso de zкато, гn $\boldsymbol{\psi} \psi$, etc., la etimología está clara; no así en el caso de жекъzo, geležis, $\chi \propto \chi$ кó $\varsigma$, etc. Si la palabra $\chi \propto \alpha-$ kós procediera de la raíz i.e. ${ }^{*} \boldsymbol{g} \boldsymbol{h}_{\boldsymbol{e l}}-(\overline{\boldsymbol{e}})-\boldsymbol{g} \boldsymbol{h}$, tendría que ser, de acuerdo con la ley de

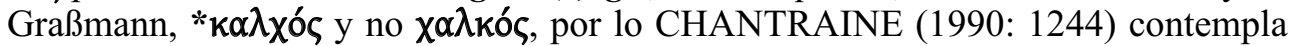
la posibilidad de que $\chi \propto \chi \lambda$ кó (y por ende жекъzo, que MACHEK (1997: 725) considera de origen "preindoeuropeo" y BUCK (1988: 613) un préstamo de origen común con la palabra griega) proceda del sum. मृच ज्ञा urudu kalga "bronce" (literalmente "cobre fuerte"), tanto más si tenemos en cuenta que la auténtica pronunciación de lo convencionalmente transcrito como kalga podría haber sido $* k k^{h}$ alka. En cuanto a los antes citados a.ing. bras, ing. brass "bronce, latón" y lat. ferrum $<^{*} \boldsymbol{b}$ ersom, se trata igualmente de palabras viajeras, que aparecen también en semí-

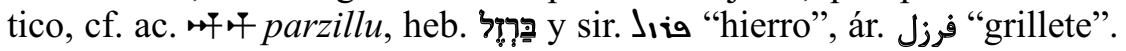

En relación con lo anterior, tenemos por un lado: a.esl. poraa, esl. ecl. pladà, rus. руда, brus. руда, ucr. руда, pol. ruda, ch. ruda, eslc. ruda, eslv. ruda, sr-cr. ruda, búlg. руда "mineral, mena, metal, mina", con sus derivados: rus. рудный, brus. рудны, ucr. рудній, pol. rudonośny, ch. rudný, eslc. rudný, eslv. rudninski, srcr. rudni, búlg. руден "metálico, mineral, minero", y, por otro, rus. y ucr. руда "sangre” y, en conexión con esto, rus. рудой, рудый, рыжий, brus. рыжы, ucr. рудий, рижий, pol. rudy, ryży, ch. rudý, eslc. rudý, "rojo, colorado, pelirrojo" y también sr-cr. rudeti "enrojecer". Por mucho que se empeñe el amigo VASMER (1987: III, 513), руда "mineral”, junto con рудный, rudný, etc. "metálico, mineral, minero", у руда "sangre", junto con рудой, rudý, ryży, "rojo", no tienen absolutamente nada que ver. En el segundo de los casos, la procedencia es la raíz i.e. * $\boldsymbol{h}_{\boldsymbol{1}} \boldsymbol{r e u d} \boldsymbol{h}_{-}$"ser

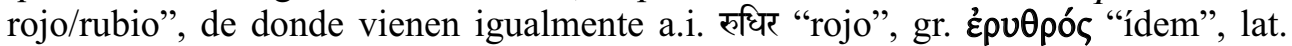
rubeus "ídem", lat. dialectal rufus "pelirrojo", gót. kan廿s “rojo", a.a.a. rōt "ídem", lit. rudas "rojo, pardo", etc. En el primero de los casos, руда "mineral", al igual que lit. rūda "ídem", alemán Erz "ídem", lat. raudus y rudus "mineral, especialmente cobre, en bruto" (la d intervocálica indica que muy difícilmente pueden proceder de $\left.{ }^{*} \boldsymbol{h}_{\boldsymbol{1}} \boldsymbol{r e u d} \boldsymbol{h}_{-}\right)$, tienen, según MACHEK (1997:522), KLUGE (1995: 232), PFEIFER (2000: 298) y otros autores, relación etimológica con sum. मृत्य urudu "cobre".

En las lenguas eslavas son frecuentes cultismos como esl. ecl. Xpürónpacz "crisoprasa", rus. хризолит "crisolita", pol. chryzantema "crisantemo", ch. у esl. chryzoberyl "crisoberilo", etc., compuestos por un elemento esl. ecl. Xoür-, rus. хриз-, brus. хрыз-, ucr. хриз-, pol. chryz-, ch. chryz-, eslc. chryz-, eslv. kriz-, srcr. hriz-, búlg. хриз-, que procede, en su caso con mediación del latín, del gr.

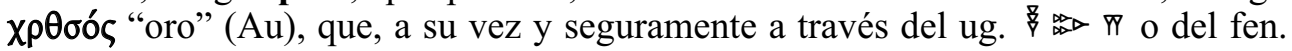

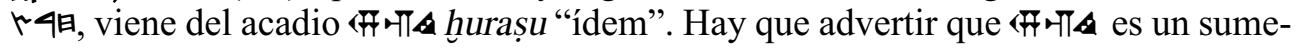
rograma que, en su caso, se translitera $k_{u g-\operatorname{sig}_{17}}[G I]$, cuyo significado literal en sumerio es "metal noble amarillo". 
El sulfuro de hierro $\left(\mathrm{FeS}_{2}\right)$ cristalizado se conoce como marcasita: rus. марказит, brus. марказіт, ucr. марказит, pol. markasyt, ch. markazit, eslc. markazit, eslv. markazit, sr-cr. markazit, búlg. марказит, término que procede del latín medie-

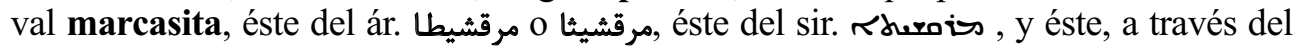

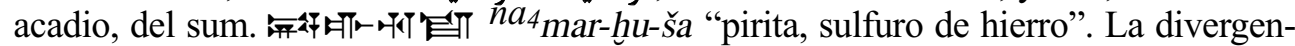
cia de forma siriaca respecto a la forma sumeria, se explica, según CORRIENTE CÓRDOBA (1999, 379), por cruce, debido a la etimología popular, con sir. حio "pulir/brillar" y con sir. rłur "dura".

Una variedad de dióxido de silicio $\left(\mathrm{SiO}_{2}\right)$ con impurezas es conocida como jaspe,

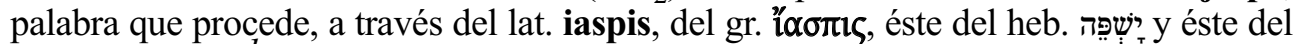

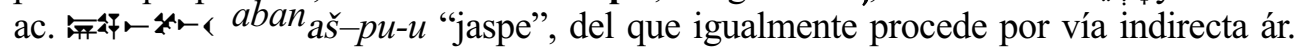
يشم يش con su doblete. Driego, en su caso a través del latín, tenemos: brus. ясыпіс, pol. jaspis, ch. jaspis, eslc. jaspis, eslv. jaspis, sr-cr. jaspis, búlg. яспис, y del árabe يشم con intermediación turania (cf. turcom. ̈̈aşma/яшмa) rus. Яшмa, ucr. Яшма.

Prosiguiendo con los petrónimos, una palabra de etimología realmente controvertida es la que designa a una variedad de sesquióxido alumínico $\left(\mathrm{Al}_{2} \mathrm{O}_{3}\right)$ conocida como "zafiro": esl. ecl. canфîpz, rus. сапфир, brus. canфip, ucr. canфip, pol. szafir, ch. safír, eslc. zafír, eslv. safir, sr-cr. safir, búlg. сапфир, que, con mediación en su caso del latín, procede del gr. ớđ $\varphi \varepsilon 1 p o \varsigma$, vocablo que seguramente llegó

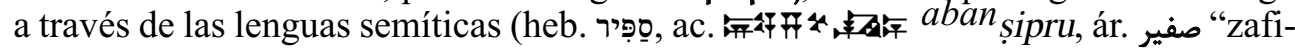
ro"). Aunque, en principio, el zafiro es una piedra azul, zafiros amarillos haberlos haylos, por lo que podría parecer plausible la procedencia de la raíz semítica $\sqrt{ }{ }_{s p r}$ (cf. ár. أصفر "amarillo"). Sin embargo, la anómala correspondencia entre sibilantes que se da en hebreo con respecto a árabe y acadio, amén de otros muchos factores que sería prolijo detallar, indican que se trata de una "palabra viajera" de origen desconocido. Curiosamente, tanto VASMER (1987: III, 566) como KLEIN (1987: 454) se hacen eco de la opinión de la posible procedencia del a.i. शानिप्रिय "el favorito de Saturno", nombre poético dado a esta piedra preciosa. En sentido contrario se pronuncia CORRIENTE CÓRDOBA (1999: 471), quien considera esta hipótesis equivocada, ya que "no es sino una etimología popular" que se dio en sánscrito a partir de la susodicha "palabra viajera".

Un internacionalismo de origen mesopotámico es la palabra "nafta": rus. нефть, brus. нафта, ucr. нафта, pol. nafta, ch. nafta, eslc. nafta, eslv. nafta, sr-cr. nafta, búlg. нефт, que proceden en última instancia del ac. vés de intermedios iranios (cf. pahl. $\boldsymbol{p}_{\text {ed }}$ naft) ha dado, por un lado, a través del gr. vó́ $\varphi \theta \alpha$, y en su caso el lat. naphtha, las formas нафта/ nafta, y, por otro, a través del far. نفت y, en su caso, del sir. نص y del ár. نفط (la intermediación del siriaco explica la $b$ del árabe a partir del pahl. نفت إص naft y frente a fambién a través de las lenguas turanias (cf. tur., az. y uz. neft, tár. нефть,) las formas нефть/нефт.

Un sinónimo de "azufre" (S) en español es el arcaísmo alcrebite, que procede del ár. الكبريت, éste del aram. כברית y éste del ac. WFभाग kib-ri-i-tu (kibrītu) "azufre", que puede igualmente escribirse mediante sumerogramas 何 ár. كبريت, sin artículo, procede el tur. kibrit "azufre" y también "cerilla, mixto, fósforo", vocablo que se ha extendido por toda el área balcánica: sr-cr. kibrit/ćibrit, búlg. кибрит, у también neogr. кıґßpítı, rum. chibrit, alb. qibrit, etc. 
Tras las "naturalia" pasemos a las "realia" y empezaremos por una serie de cognados de etimología controvertida: a.esl. къйнга, esl. есl. кни́га, rus. книга, brus. кніга, ucr. книга, pol. księga, ch. kniha, eslc. kniha, eslv. knjiga, sr-cr. knjiga, búlg. книга "libro", a los que habría que añadir también húng. könyv "ídem". Entre las diversas hipótesis que se han barajado, se cuenta la de la procedencia del ac.

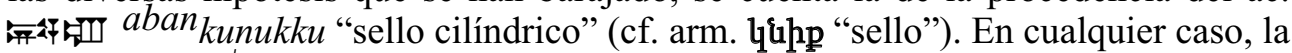
raíz semítica $\sqrt{ } k n k$ es anómala y está mal representada, por lo que lo más probable es que ya en acadio fuera una "palabra viajera".

Latinismos como rus. табель "tabla, cuadro, lista", таблетка "tableta", таблица "tabla, cuadro, lista", brus. таблетка "tableta", табліца "tabla, cuadro, lista", ucr. таблетка "tableta", таблица "tabla, cuadro, lista", pol. tabletka "tableta" tablica "tabla", ch. tabletka "tableta", tabule, eslc. tabletka "tableta", tabul'a "encerado", eslv. tabla, tableta "tableta", sr-cr. tabla "encerado", tableta "tableta", búlg. табла "tabla", таблетка "tableta", таблица "tabla, cuadro, lista", etc., tienen como étimo lat. tabula, que, a través del etrusco y de otras lenguas, procede en última instancia del sum. H्ञाT $d u b$ "tablilla, documento".

Restringidos al espacio central del territorio eslavo están los cognados: ucr. куфер, pol. kufr, ch. kufr, eslc. kufor, sr-cr. kofer "baúl, maleta" que proceden del al. Koffer (o bien de la forma arcaica/dialectal Kuffer), éste del fr. coffre "cofre, arca, baúl", éste del lat. cophinus, éste del gr. kó $\varphi$ ivoৎ "cesto, canasta", éste del

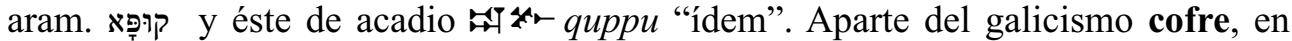
español existen los dobletes cuévano, procedente del griego a través del latín, y cofa, procedente del arameo a través del ár. ققّ "serón, espuerta".

La medida para vodka equivalente a 0,3 litros, se llama en ruso косуха о косушка, término que entró por mediación turania (cf. uzb. kosa/коса) procenden-

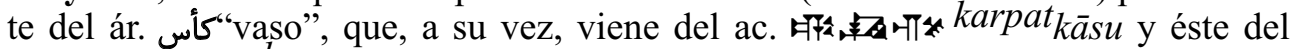

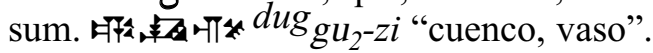

En lo referente a las etimologías de sidra y yeso, remitimos al lector a ALVARADO (2006: 193-194 y 191-192).

La principal y más famosa ciudad de Mesopotamia en la antigüedad fue

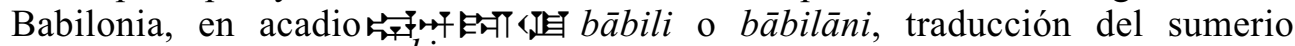

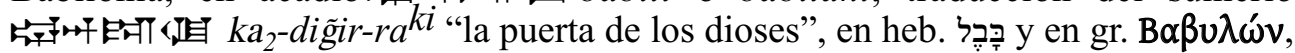
topónimo que, en la tradición occidental según Vulgata, ha dado el doblete Babel/Babylon, de modo que en las lenguas eslavas aparece: a.esl. вавкконъ, esl. ecl. вавӥми́нz, rus. Вавилон, brus. Вавілон, исr. Вавилон, pol. Babel/Babilon, ch. Bábel/Babylón, eslc. Bábel/Babylon, eslv. Babel/Babilon, sr-cr. Babel/Babilon, búlg. Вавилон, у no sólo esto. Por aquello de la Torre de Babel (Gn XI, 1-9), gracias a la cual filólogos, lingüistas, profesores de idiomas, traductores, dragomanes y demás chusma indeseable podemos ganarnos el sustento, Babilonia se ha convertido en el paradigma de la confusión, cuando no en el del lujo, la corrupción y el desenfreno (cf. ApJn XVIII, 1-24), y esto ha pasado al campo de la fraseología. En ruso, por ejemplo, existe el fraseologismo вавилонское столпотворение, en búlgaro вавилонско стълпотворение, literalmente "pirgodómesis ${ }^{1}$ babilónica", que sig-

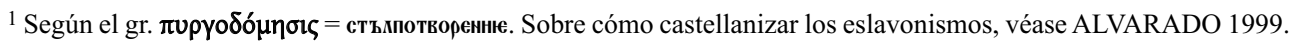


nifica "confusión, desorden, barullo, guirigay". Igualmente en ruso tenemos el sustantivo plural вавилоны "garrapatos, letras ilegibles". En checo y eslovaco, por su parte, existe la expresión bábelský/babylónský zmatek - bábelský/babylonský zmätok "confusión babélica o babilónica" y así sucesivamente en todas las lenguas eslavas, así como las restantes lenguas de los pueblos de tradición judeocristiana.

Babilonia estaba situada en la región conocida como Caldea: a.esl. халъдћћ, esl. есl. Хамде́я, rus. Халдея, brus. Халдэя, ucr. Халдея, pol. Chaldea, ch. Chaldea, eslc. Chaldea, eslv. Kaldeja, sr-cr. Kaldeja, búlg. Халдея, del griego Х $\alpha \lambda \delta \alpha i ́ \alpha$, en

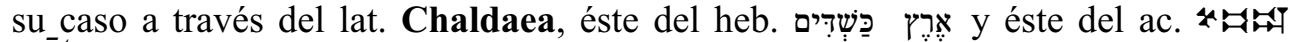
$m \bar{a} t$ Kašdu/Kaldu "Caldea", literalmente "la tierra conquistada". La la sustitución de š $<$ ś por 1 ante dental una característica de los dialectos neo-babilónicos y tendría su explicación por la posible resonancia lateral de $\dot{s}^{*}<\underline{*}$ en protosemítico (MOSCATI, 1980, 33-35).

Al norte de Caldea se encontraba Asiria: a.esl. acrphrt, esl. ecl. âcr \&́pz, rus. Ассирия, brus. Асірыя, ucr. Ассирія, pol. Asyria, ch. Asýrie, eslc. Asýria, eslv. Asirija, sr-cr. Asirija, búlg. Асирия, del del griego 'Aбoupía, en su caso a través

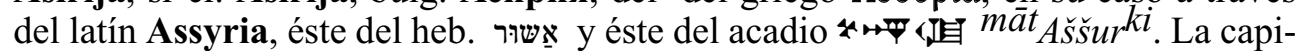
tal de Asiria era Nínive: a.esl. нннекн, esl. есl. нӥнеvía rus. Ниневия, brus. Ніневія, ucr. Ніневія, pol. Niniwa, ch. Ninive, eslc. Ninive, eslv. Ninive, sr-cr. Niniva, búlg. Ниневия, del griego Nivevń, en su caso a través del lat. Nineve, éste del heb. נִינְונה

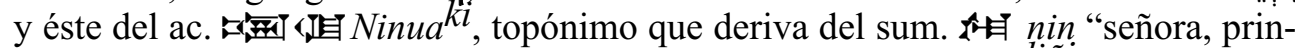
cesa" (en acadio se lee belltu), en clara alusión a la diosa mor dig̃ir Ininni/Inanna (en acadio ${ }^{i l}{ }_{I s ̌ t}$ tar), una de la principales deidades del panteón mesopotámico y patrona de dicha ciudad.

Otros topónimos mesopotámicos recogidos en la Biblia son, p. ej., Acad y Erec.

Acad: esl. ecl. àpxáaz, rus. Аккад, brus. Акад, исr. Аккад, pol. Akkad, ch. Achad, eslc. Akkad, eslv. Akád, sr-cr. Akad, búlg. Акад, del lat. Accad (en LXX aparece la forma $A p x \alpha \delta$, que recoge fielmente el eslavo eclesiástico), éste del heb.

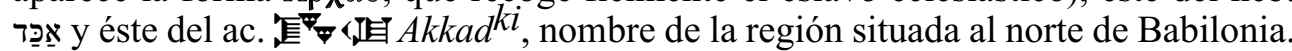

Erec: esl. ecl. ópéxz, rus. Эpex, brus. Эрэx, ucr. Epex, pol. Erek, ch. Erech, eslc. Erech, eslv. Ereh, sr-cr. Erek, búlg. Epex, del lat. Erech (en LXX aparece la forma OpEX, que recoge fielmente el eslavo eclesiástico), éste del heb. ארך y éste del ac.

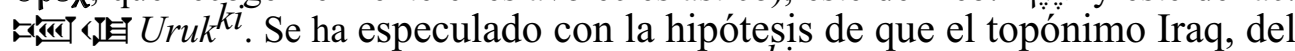

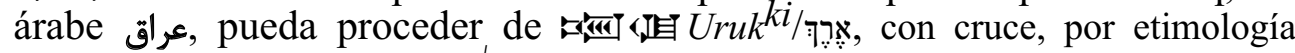
popular, con la raíz semítica $\sqrt{ }$ $r q$ en su sentido de "brotar a causa de la humedad, arraigar la vegetación".

Según se narra en Génesis X, 10, Babel, Erec y Acad estaban situadas en la tierra de Senaar: a.esl. сенарь, esl. ecl. геннаápz, rus. Сеннаap, brus. Сэнаap, ucr. Шiнeap, pol. Szinear, ch. Sinear, eslc. Šineár, eslv. Šinár, sr-cr. Šinear, búlg. Сенаap, topónimo que prodece del del griego $\Sigma \varepsilon v v \alpha \alpha \rho$, en su caso a través del latín

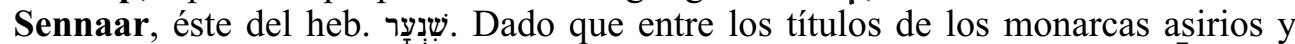
babilonios se contaba el de: $\left({ }^{2} u\right.$ Eme-gir $\left._{15}\right) u_{3} A k k a d k i$ "rey de Sumeria y Acad" y dado que en la Biblia no se cita a Sumeria como tal, es opinión común, dado además el problema de la deficiente notación de las laringales en acadio, que שְְִׁעָר no es sino la adaptación hebrea de 


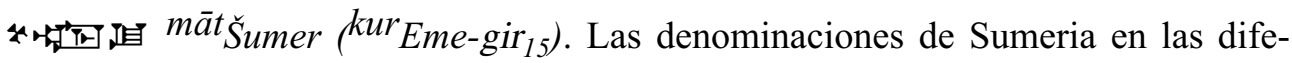
rentes lenguas eslavas son: rus. Шумер, brus. Шумэр, ucr. Шумер, pol. Sumer, ch. Sumer, eslc. Sumer, eslv. Sumerija, sr-cr. Sumer, búlg. Шумер.

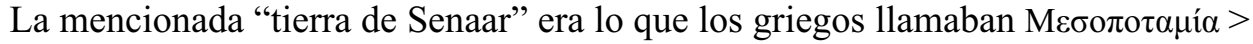
Mesopotamia, es decir, el territorio situado, como su nombre indica, entre dos ríos, el Tigris y el Éufrates. El hidrónimo Tigris: a.esl. тнгръ, esl. ecl. тїрð, rus. Тигр, brus. Тыгр, ucr. Тигр, pol. Tygrys, ch. Tigris, eslc. Tigris, eslv. Tigris, sr-cr.

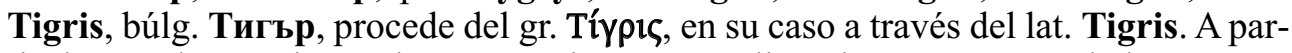
tir de aquí la cuestión se hace auténticamente peliaguda, pues, por un lado tenemos el nombre de este río en a.pers. $=Y_{Y} Y$ r $\langle Y Y Y$ Tigra y, por otro, las denominaciones

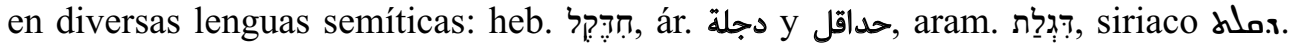
Comparando el griego y el antiguo persa con las lenguas semíticas, nos encontramos una secuencia dental (dándose significativamente la correspondencia sorda en las lenguas indoeuropeas/sonora en las lenguas semíticas, cf. MØLLER, 1917: 6 y ALVARADO, 2007: 79-80), vocal i (en esto están todos de acuerdo), velar y líquida, con una faringal inicial en el hebreo en uno de los nombres árabes. Tanto por lo que se acaba de exponer como por los testimonios históricos se infiere que todos estos hidrónimos proceden en última instancia del ac. Tât Idiglat y éste del sum. Tor id Idigna. Según HALLORAN (2006: 120) el nombre sumerio procedería de $i d_{2}$ "río" $+i_{3}$ "morfema verbal impersonal" + gen "ir" $+a$ "desinencia de nominativo", significando, por tanto, "el río que va" debido a la rapidez de su corriente. Dada la imperfección y arbitrariedad de la grafía cuneiforme, no sabemos que habría detrás de $\bar{\uparrow} \mathrm{id}_{2}$ en relación con la faringal ha que aparece tanto

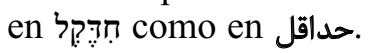

Por su parte, el hidrónimo Éufrates: a.esl. юфратъ, esl. ecl. Êvфpátz, rus. Евфрат, brus. Эўфрат, ucr. Євфрат, pol. Eufrat, ch. Eufrat, eslc. Eufrat, eslv. Evfrat, sr-

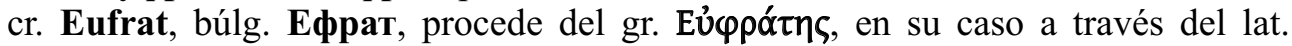
Euphrates, y éste en última instancia, al igual que ocurre con heb. y aram.

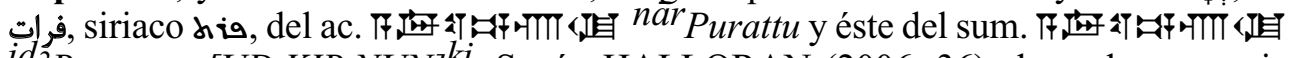
${ }^{i d_{2}}$ Buranum [UD.KIB.NUN] ${ }^{k i}$. Según HALLORAN (2006: 36) el nombre sumerio procedería de $b u_{5}$, "correr" + $r a$ "desbordarse"+ nun "grande, noble".

El Tigris y el Eufrates era dos de los cuatro ríos que, según Gn II, 8-15 regaban el jardín plantado en Edén: a.esl. єедем esl. ecl. єеле́мz, rus. Едем, brus. Эдэм, ucr. Едем, pol. Eden, ch. Eden, eslc. Éden, eslv. Eden, sr-cr. Eden, búlg. Едем, topónimo que prodece del del griego $E \delta \varepsilon \mu$, o en su caso del latín Eden, éstos del heb. עִדֶ, topónimo de etimología ciertamente controvertida, habiéndose desde hace tiempo (cf. LANDERSDORFER, 1916: 51) barajado la posibilidad de que prodeda del sum. Ea edin, que HALLORAN (2006: 59) define como "steppe, plain, desert; land between the two long rivers", es decir, "estepa, llanura, desierto; tierra entre los dos largos ríos", considerándolo un compuesto de

En correspondencia con otras muchas lenguas, en ruso y búlgaro para ponderar una francachela por todo lo alto se emplea el fraseologismo bíblico Валтасаров пир "el festín de Baltasar", que hace alusión a Dn V 1-30. El antropónimo Baltasar: a.esl. валтасаръ, esl. ecl. валтага́pz, rus. Валтасар, brus. Валтасар, ucr. Валтасар, pol. Baltazar, ch. Baltazár, eslc. Baltazár, eslv. Baltazar, sr-cr. Baltazar, búlg. 


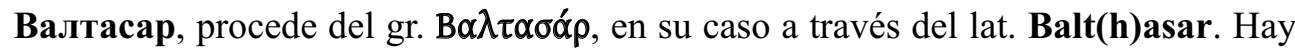
que hacer notar que en arameo imperial, lengua en la que fue redactado el mencionado capítulo $\mathrm{V}$ del libro del profeta Daniel, el nombre del último monarca caldeo

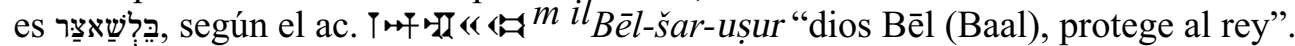

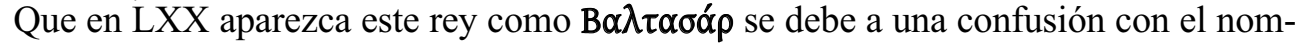
bre que el jefe de los eunucos de la corte babilónica dio al profeta Daniel (cf. Dn I, 67), nombre que en arameo es Se barajan dos posibles etimologías para el nombre arameo

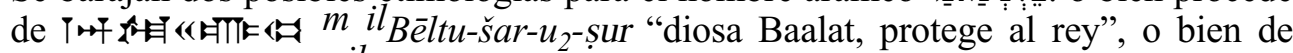

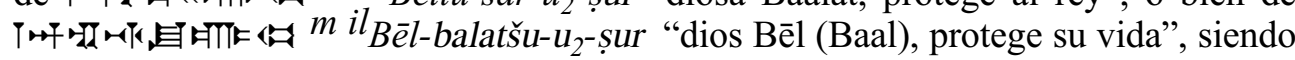
ușur la $2^{\mathrm{a}}$ pers. masc. sing. del imperativo de la forma I (qal) de nașāru "proteger".

Haciendo un inciso, hay que indicar que en la Biblia son citados otros monarcas y altos dignatarios mesopotámicos:

Asarhadón: esl. ecl. сахєрАа́нz, rus. Сахердан/Асархаддон, brus. Асархаддон, ucr. Сахердон, pol. Asarhaddon, ch. Esarchadón, eslc. Assarhaddon, eslv.

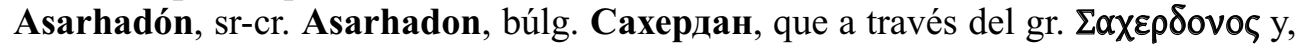

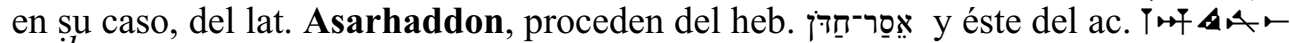
$m$ il Ǎšsur-aha-iddin "Aššur dio un hermano", siendo iddin, representado en este caso por el sumerograma $\curvearrowleft \mathrm{AS}$, la $3^{\mathrm{a}}$ pers. masc. sing. del pretérito de la forma I (qal) del verbo nadānu "dar".

Evilmerodac: esl. ecl. êvï̀mаршаáxz, rus. Евилмеродах, brus. Эвілмэродах, ucr. Евіл-Меродах, pol. Ewil-Merodak, ch. Evilmerodach, eslc. Evíl-Meródach, eslv. Evíl Merodáh, sr-cr. Evil Merodak, búlg. Евилмеродах, que a través del gr.

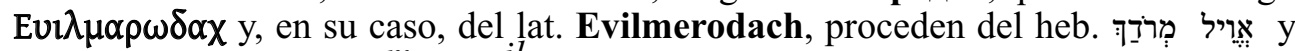
éste del ac. Tha

Merodac Baladán: esl. ecl. маршаáxz вамадáнz, rus. Беродах Баладан, brus. Бэродах Баладан, ucr. Меродах Баладан, pol. Merodak-Baladan, ch. Berodach Baladan, eslc. Beródach Baladan, eslv. Merodáh Baladán, sr-cr. Merodak-Baladan, búlg. Беродах Баладан, que a través del gr. М $\alpha \omega \omega \delta \alpha \chi \beta \alpha \lambda \alpha-$ $\delta \propto v$ y, en su caso, del lat. Berodach Baladan, proceden del heb. מרוֹ y

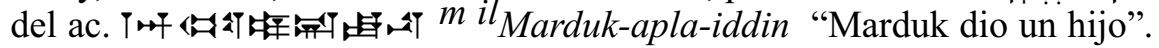

Nabucodonosor: esl. ecl. нав8ходоно́ropz, rus. Навуходоносор, brus. Навухаданосар, ucr. Навуходоносор, pol. Nabuchodonozor, ch. Nabuchodonozor, eslc. Nebúkadnecar, eslv. Nebukadnezar, sr-cr. Nabukodonozor, búlg. Навуходоносор, que a través, en su caso, del gr. Naßouxo-

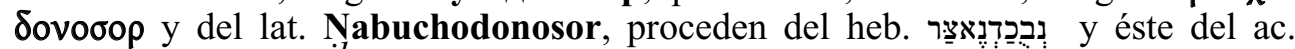
$m{ }^{2}$ Nabu-kudurri-ușur "dios Nabū, protege la frontera", siendo uṣur la $2^{a}$ pers. masc. sing. del imperativo de la forma I (qal) de nașāru "proteger", representado en este caso mediante el sumerograma ŠS.

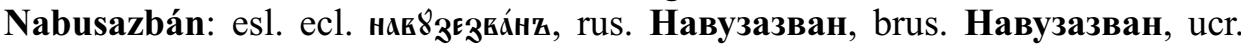
Невушазбан, pol. Nebuszazban, ch. Nebušazban, eslc. Nebúšazbán, eslv.

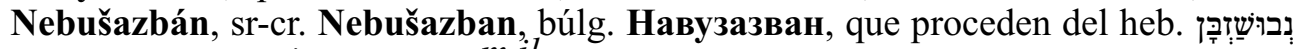

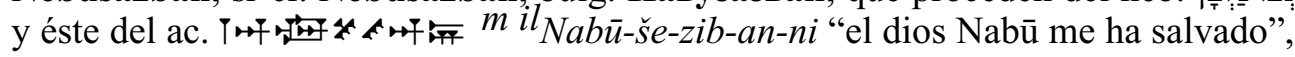
siendo šezib la $3^{\mathrm{a}}$ pers. masc. sing. del permansivo de la forma III (šafYel) de ezēbu "soltar, dejar" y en forma III "salvar, rescatar". 
Nabuzaradán: esl. ecl. нав४з̧ара́́нz, rus. Навузардан, brus. Навузардан, ucr. Невузардан, pol. Nebuzaradan, ch. Nebuzardan, eslc. Nebúzaradán, eslv. Nebuzaradán, sr-cr. Nebuzaradan, búlg. Навузардан, que a través, en su caso,

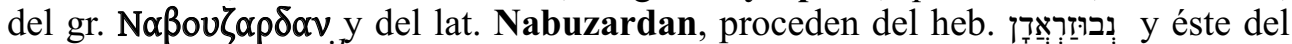
ac. Tr干

Nergalsaréser: esl. есl. ннргєлгарага́pz, rus. НергалШарецер, brus. НэргалШарэцэр, ucr. Нергалсарецер, pol. Nergal-sar-eser, ch. Nergalisaretser, eslc. Nérgal-Serecer, eslv. Nergál Sarécer, sr-cr. Nergal Sar-Eser, búlg. Нергал-

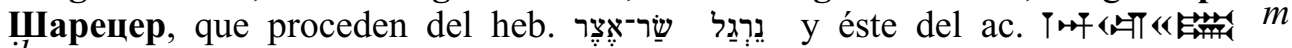

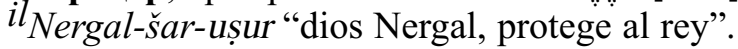

Salmanasar: esl. ecl. самманаста́pz, rus. Салманассар, brus. Салманасар, ucr. Салманассар, pol. Salmanassar, ch. Salmanazar, eslc. Šalmaneser, eslv. Salmansar, sr-cr. Salmanassar, búlg. Салманасcap, que a través, en su caso, del

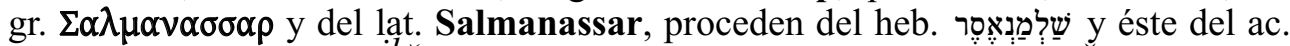

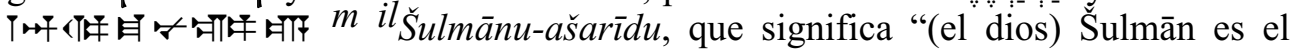
supremo".

Sargón: esl. ecl. àpнà, rus. Саргон, brus. Саргон, ucr. Саргон, pol. Sargon, ch. Sargon, eslc. Sargon, eslv. Sargon, sr-cr. Sargon, búlg. Саргон, que a través del lat. Sargon (Apva en LXX es un error de copista que recoge fielmente el eslavo

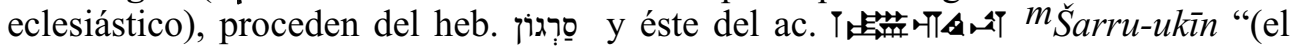
dios de turno) ha establecido al rey", siendo $u k \bar{n}$, representado mediante el sumerograma GI.NA, la $3^{\text {a }}$ persona del singular masculino del pretérito de la forma II (pifel) del verbo kānu "ser".

Senaquerib: esl. ecl. сеннаүндїмz rus. Сеннахирим, brus. Сэнахірым, ucr. Санхериб, pol. Sennacheryb, ch. Sancherib, eslc. Senacherib, eslv. Sanheríb, srcr. Sanherib, búlg. Сенахирим, antropónimo que, a través, en su caso, del latín Sennacherib o el griego $\Sigma \varepsilon v v \propto \chi \chi \eta \rho \iota \mu$, grafía corrupta por $\Sigma \varepsilon v v \propto \chi \eta \rho \imath \beta$, procede del

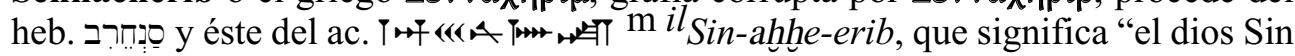
remplazó (por mí) a los hermanos (fallecidos)", siendo erib, representado mediante el sumerograma GI, la $3^{\text {a }}$ persona del singular masculino del pretérito de la forma I (qal) del verbo râbu (riabu) "remplazar, restituir".

Teglatfalasar: esl. ecl. вагмафамласа́pz, rus. Феглафелласар, brus. Тэглафэласар, ucr. Тіглатпілесар, pol. Tiglat-Pileser, ch. Tiglatfalazar, eslc. Tiglat-Pilneser, eslv. Tilgat-pilneser, sr-cr. Tiglat Pileser, búlg. Теглатфеласар,

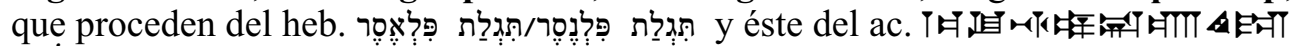
$m$ ișTukul-ti-apil-E $E_{2}-\check{s} a r_{2}$-ra "Mi socorro es el hijo de Ešara".

Otro fraseologismo de origen mesopotámico documentado en ruso es царь царем "suntuosamente, magníficamente, a cuerpo de rey" (ДАЛЬ, IV, 1882:570),

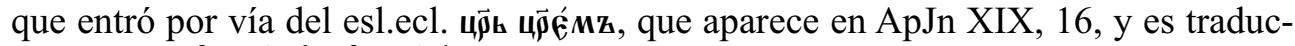
ción de gr. $\beta \alpha \sigma \imath \lambda \varepsilon \dot{\varepsilon} \varsigma \beta \alpha \sigma \imath \lambda \varepsilon ́ \omega v$, el cual, a su vez, procede de la expresión aramea

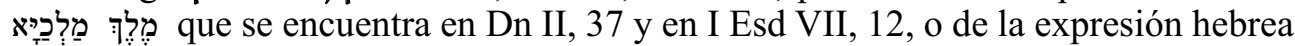

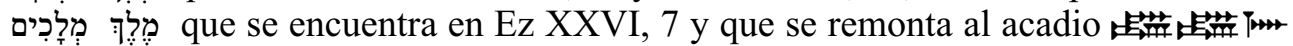
šar šarrāni "rey de reyes", superlativo perifrástico semítico que viene a significar "monarca supremo", es decir, "emperador", y que Sargón I el Grande (2334 a.C. 2279 a.C.), fundador del Imperio Acadio, adoptó como título real, pasando luego a 
sus sucesores. Tras la caída de Babilonia en el año 539 a.C., Ciro II el Grande (reg. 559 - 530 a. C.) se apropió de este título regio en la forma

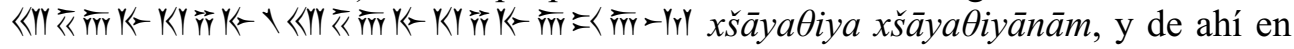
adelante, pues los monarcas del Oriente han seguido empleando dicho título hasta tiempos muy recientes, siendo los últimos en ostentarlo los dos autócratas derroca-

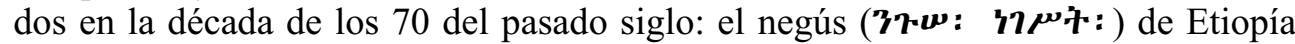

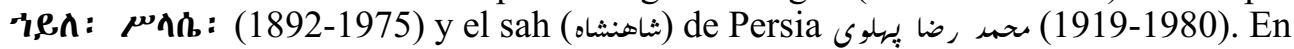
cuanto al ruso царь царем, en primer lugar hace referencia a un género de iconos que, según los mencionados versículos del Apocalipsis de San Juan, representan a Jesucristo en toda su gloria, ataviado con vestiduras regías y una corona o mitra en la cabeza, por lo que, tomada adverbialmente, tal expresión es figurada, coloquial y un puntito irreverente.

La antes mencionada Torre de Babel no era sino un "zigurat": rus. зиккурат, brus. зікурат, uсr. зиккурат, pol. ziggurat, ch. zikkurat, eslc. zikkurat, eslv. zigurat, sr-cr. zigurat, búlg. зиккурат, historicismo que procede en última instancia de 〈F-FाT: que en sumerio se lee $u_{6}$-nir [IGI.E $E_{2}$.NIR] y en acadio ziqqurratu, dever-

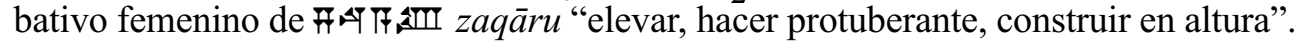

Prosiguiendo con términos arquitectónicos, hay uno que recoge MACHEK (1997:46), cuyo supuesto origen sumero-acadio es más que discutible: rus. барак, brus. барак, ucr. барак, pol. barak, ch. barák, eslc. barák, eslv. barak, sr-cr. barak, búlg. барак "barraca, barracón militar" que, a través del al. Baracke y el fr. baraque, proceden del esp. barraca. Hasta aquí, de acuerdo. Pero MACHEK, siguiendo a P. Aalto (Neuphilologische Mitteilungen, Helsinki, 39.383), pretende que barraca, a través del sir. $\sim$ حi "santuario, capilla" procede del acadio parakku y éste del sumerio bara "sala, estancia, celda" que le falta es el detalle de demostrar por qué vías pudo pasar del siriaco al español.

Otro caso semejante de etimología mesopotámica más o menos inverosímil, también recogido por MACHEK (1997: 651), haciéndose eco de una hipótesis del famoso orientalista Bedřich Hrozný (1879-1952), según la cual, a.esl. тpłř, esl. ecl. то́ргz, rus. торг, brus. торг, ucr. торг, pol. targ, ch. trh, eslc. trh, eslv. trg, sr-cr. trg, búlg. търг "mercado", al igual que lit. turgus, let. tirgus y alb. tregë "ídem", así como los topónimos Turku en Finlandia, Torgau en Alemania y Trieste en Italia, tendrían origen mesopotámico. En efecto, puede afirmarse que los sumerios, antes incluso que los fenicios, fueron los inventores del comercio y la palabra dam-gar "comerciante", pasó al ac. amgāru "ídem" y de éste a otras

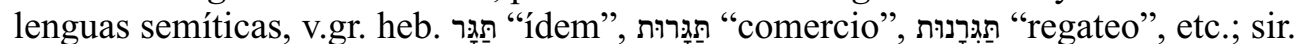
il "comerciante", dazld "comercio", تلاجر "comerciânte", تجارة "comercio", متجرة "mercado", etc., etc. Si el paso del sumerio a las lenguas semíticas es, por cuestiones fonéticas, geográficas y cronológicas, fácilmente explicable, el supuesto paso de las lenguas semíticas a las indoeuropeas necesita una demostración mucho más convincente, en especial en lo referente al consonantismo y al vocalismo, que la que aparece en MACHEK (1997: 651).

\footnotetext{
${ }^{2}$ La fonética del acadio se explica, como en otros varios casos, a partir de la forma de genitivo sumeria bara $_{2}-a k$.
} 
En VASMER (1987: III, 31) está recogida el historicismo пópoк, en a.rus. nopokz "ariete" (cf. pol. prok "ídem" ch. prak, eslc. prak "catapulta"), que tiene relación etimológica con a.esl. праща, rus. праща "honda", y, al parecer, también con a.i.

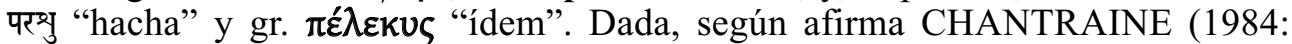
875) la correspondencia exacta de la palabra griega con la palabra sánscrita, junto con su estructura no indoeuropea, se pensó en un posible préstamo semítico. Así lo recoge VASMER, el cual hace remontar la etimología de порок a un supuesto acadio **pilaqqu "daga, puñal", lo que no parece muy acertado por dos razones fundamentales:

$1^{\mathrm{a}}$ ) porque "puñal" y, a mayor abundamiento, va precedido del determinativo

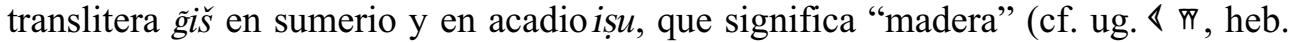
빠, gz. óde) y que, tal como se ha explicado más arriba, se emplea para indicar objetos de madera.

$\left.2^{\mathrm{a}}\right)$ porque la transliteración tiene que ser pilakku y no ** pilaqqu. Aunque el sistema gráfico del acadio es muy imperfecto, pues adaptó la escritura de una lengua en la que, como también se ha explicado más arriba, es probable que no hubiera oclusivas sonoras, y entre las oclusivas sordas se diera la oposición fuerte/lene o, en su caso, aspirada/no aspirada, a una lengua en la que, como en todas las del tronco semítico, se daba la triple oposición sorda/sonora/enfática ${ }^{4}$, se puede establecer que la transliteración correcta de $\boldsymbol{n}^{-4 \hat{z}}$ es pilakku y no **pilaqqu por comparación con

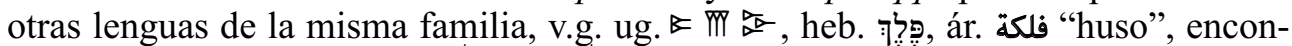
trándose en todos los casos, $\sqrt{ } k$ y no $\sqrt{q}$.

No es descartable, sin embargo, que порокъ, порок, prok, prak, etc., puedan tener una remota etimología semítica, ya que de la matriz bilítera $* \boldsymbol{p l} /{ }^{*} \boldsymbol{p r}$ derivan varias raíces trilíteras $\sqrt{ }$ prg, $\sqrt{ }$ prd, $\sqrt{ }$ prss, $\sqrt{ }$ prq, $\sqrt{ }$ plg, $\sqrt{ }$ plh, etc., con los sentidos de "separar", "dividir", "hender", "partir", "apartar", "rajar" etc. Tal hipótesis, obviamente, necesita una profunda investigación, que sobrepasaría, con mucho, los fines y límites de este trabajo.

Los arcaísmos тандыр en ruso у тандър en búlgaro "hornillo de barro, atanor" proceden del tur. tandır, éste del far. تندور, que, con disimilación de dentales, procede del ár. تنور صنور patanor". En farsí existe igualmente el doblete تنور procede del pahl.

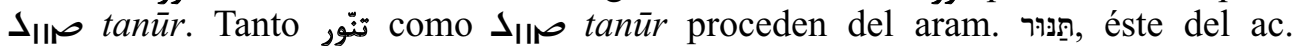

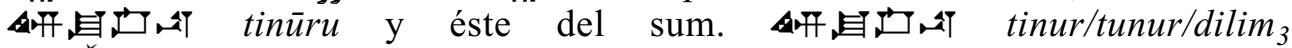
[IM.ŠU.LAGAB.NA] "atanor, horno de arcilla".

Arabismos de difusión internacional son las palabras "muftí": rus. муфти, brus. муфті, ucr. муфті, pol. mufti, ch. mufti, eslc. mufti, eslv. mufti, sr-cr. mufti, búlg. муфти, у "fetua": rus. фетва, brus. фетва, ucr. фетва, pol. fatwa, ch. fetva, eslc. fetva, eslv. fetva, sr-cr. fetva, búlg. фетва. Tales arabismos, sin embargo, proceden en última instancia del acadio. Así, مفت "jurisconsulto musulmán” es el participio activo de أفنى "dictaminar, responder a una consulta legal”, de donde procede igual-

\footnotetext{
${ }^{3}$ Como en el caso anterior, la fonética del acadio se explica a partir de la forma de genitivo sumeria 由以絓再 gišbala-ak.

${ }^{4}$ Así, p. ej., जा/2, que en sumerio se translitera $g a$, en acadio se puede transliterar como $g a$, como $k a_{3}$ y como $q a_{2}$
} 
mente el sustantivo فتوة "dictamen de un jurisconsulto", todo lo cual, a través del arameo, viene del ac. - Hấ petū uzna "explicar", lit. "abrir el oído", siendo m petū "abrir" la forma acadia, con pérdida de la faringal sorda de la raíz semítica $\sqrt{ }$ pth,

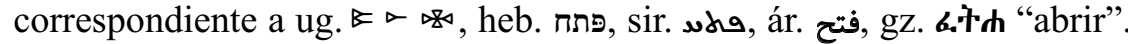

Por su parte, uno de lo hebraísmos más extendidos es la palabra sábado: a.esl. спевота, совота, esl. ecl. с४вки́та, rus. суббота, brus. субота, ucr. субота, pol. sobota, ch. sobota, eslc. sobota, eslv. sobota, sr-cr. subota, búlg. събота, que en última instancia derivaría del ac. 预 šabatu [TUŠ] “descanso". Para más detalles, remito al lector a ALVARADO (2001).

Para terminar, hay que hablar de la palabra sumeria según según LEHMANN (1986: 46), y tanto más teniendo en cuenta que, como ya se ha dicho, la $d$ de la transliteración sin duda representa una oclusiva sorda, tendría relación con el gót. дтT отец, brus. айцец, ucr. отець, pol. ојсіec, ch. otec, eslc. otec, eslv. ос̌е, sr-cr. otac, búlg. отец "padre". Tal relación etimológica es perfectamente plausible, ya que, obviamente se trata de un vocablo de los que en lingüística se denominan "nursery words", que quizá proceda del fondo más antiguo del lenguaje humano y que encuentra homólogos en otras lenguas, tanto indoeuropeas (hit. 时, 可 at-taš "padre",

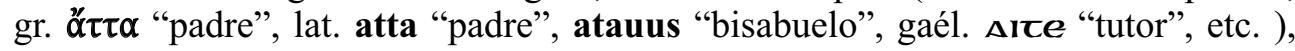
como no indoeuropeas (húng. atya "padre", tur. آتا ata "padre", vasc. aita "padre", mon. эцэг "padre, etc.).

\section{AGRADECIMIENTO}

Al Dr. D. Federico Corriente Córdoba por la amabilidad y la solvencia con que ha atendido mis consultas.

\section{ABREVIATURAS}

a.a.a. $=$ antiguo alto alemán, ac. $=$ acadio, a.esl. $=$ antiguo eslavo, a.i. $=$ antiguo indio, a.ing. $=$ antiguo inglés, a.nór. $=$ antiguo nórdico, al. $=$ alemán, alb. $=$ albanés, ár. $=$ árabe, a.rus. $=$ antiguo ruso, b.lat. $=$ bajo latín, brus. $=$ bielorruso, búlg. $=$ búlgaro, $\mathrm{ch} .=$ checo, esl. ecl. $=$ eslavo eclesiástico, eslc. $=$ eslovaco, eslv. $=$ esloveno, esp. $=$ español, fen. $=$ fenício, fr. $=$ francés, gaél. $=$ gaélico, gót. $=$ gótico, gr. $=$ griego, gz. $=$ guéez, heb. $=$ hebreo, hit. $=$ hitita, húng. $=$ húngaro, ing. $=$ inglés, lat. $=$ latín, mon. $=$ mongol, neogr. $=$ neogriego, pahl. $=$ pahlevi, pol. $=$ polaco, rum. $=$ rumano, rus. $=$ ruso, sir. $=$ siríaco, sr-cr. $=$ serbio-croata, sum. $=$ sumério, tur. $=$ turco, turcom. $=$ turcomano, ug. $=$ ugarítico, ucr. $=$ ucraniano, vasc. $=$ vascuence

\section{Referencias bibliográficas}

ALVARADO SOCASTRO, S. (1999): "Sobre la castellanización de los eslavismos y otros asuntos que afectan a los neologismos en nuestra lengua", Boletín de la R.A.E. Tomo LXXIX - Cuaderno CCLXXVI, pp. 151-176.

ALVARADO SOCASTRO, S. (2001): "Sobre la nomenclatura eslava de la semana y sus días en las lenguas eslavas y en otras lenguas", Boletín de la Asociación Española de 
Orientalistas, Año XXXVII, Madrid, pp. 193-209.

ALVARADO SOCASTRO, S. (2006): "Sobre el léxico de origen egipcio en las lenguas eslavas, en español y en otras varias lenguas (I)", Eslavística Complutense, 6, pp. 183-200.

ALVARADO SOCASTRO, S. (2007): "Sobre el léxico de origen egipcio en las lenguas eslavas, en español y en otras varias lenguas (y II)", Eslavística Complutense, 7, pp. 77-87.

BUCK, C. D. (1988): A dictionary of selected synonims in the principals indo-europeans languages, The University of Chicago Press, Chicago.

CHANTRAINE, P. (1990): Dictionnaire étymologique de la langue greque, Klincksieck, París.

CORRIENTE CÓRDOBA, F. (1999): Diccionario de arabismos y voces afines en iberorromance, Gredos, Madrid.

DELITZSCH, F. (1914) : Sumeriches Glossar. J. C. Hinrich. Leipzig.

ELLERMEIER, F. (1979): Sumerisches Glossar, Selbstverlag F. Ellermeier, Göttingen.

HALlORAN, J. A. (2006): Sumerian Lexicon, Logogram Publishing, Los Ángeles, California.

HARPER, D. (2011): Online Etymology Dictionary, http://www.etymonline.com/

KLEIN, E. (1987): A Comprehensive Etymological Dictionary of the Hebrew Language, Carta, Jerusalén.

KLUGE, F. (1995): Etymologisches Wörterbuch der deutschen Sprache. 23. Auflage, De Gruyter, Berlín-Nueva York.

LANDERSDORFER, P. S. (1916): Sumerisches Sprachgut im Alten Testament, J. C. Hinrich, Leipzig.

LEHMANN, W. P. (1986): A Gothic Etymological Dictionary, Leiden, Brill.

MACHEK, V. (1997): Etymologický slovník jazyka českého a slovenského, Lidové noviny, Praga.

MØLLER, H. (1917): Die Semitisch-Vorindogermanischen laryngalen Konsonanten, Kgl.Hof-Boghandel, København.

MOSCATI, S. (ed.) (1980): An introduction to the comparative grammar of the Semitic Languages, Otto Harrassowitz, Wiesbaden.

PARPOLA, S., R. WHITING (eds.) (2007): Assyrian-English-Assyrian Dictionary, Universiy Press, Helsinki.

PFEIFER, W. (red.) (2000): Etymologisches Wörterbuch des Deutschen, Deutscher Taschenbuch Verlag, Munich.

SODEN, W. Freiherr von (1965): Akkadisches Handwörterbuch. Band. I-II-III, Otto Harrassowitz, Wiesbaden.

VASMER, M. (1986-87): Этимологический словарь русского языка, Тома I-IV, Прогресс, Москва.

ДАЛЬ, В. И. (1978-80): Толковый словарь живаго великорусскаго языка. Тома I-IV, Русский язык, Москва. 